\title{
Supergene gold transformation in technogenic mineral formations
}

\author{
Alfiia Khusainova ${ }^{1,2, *}$, Vladimir Naumov $^{3}$, and Oksana Naumova ${ }^{3}$ \\ ${ }^{1}$ Sobolev Institute of Geology and Mineralogy of the Russian Academy of Sciences (IGM SB RAS), \\ 630090, pr. Akademika Koptyuga 3, Novosibirsk, Russia \\ ${ }^{2}$ Novosibirsk State University (NSU), Department of Geology and Geophysics, 630090, 2 Pirogova \\ Str., Novosibirsk, Russia \\ ${ }^{3}$ Perm State University (PSU), Geology Department, 614990, 15 Bukirev Str., Perm, Russia
}

\begin{abstract}
This article is about the research on gold obtained from mine wastes and other technogenic mineral formations. The authors investigated how solid phases of gold in supergene zone transform from various deposits. Results show the following supergene gold transformations by various physical, chemical, biological and mechanical processes occurring in the wastes. Transformations result in changes in morphology and chemical composition, and special redistribution of gold in wastes.
\end{abstract}

\section{Introduction}

The problem of scales for dissolution processes, transformation and origin of gold in the supergene zone is discussed [1-6]. Therefore, we investigate the behavior of gold in the supergene zone; the example of this is technogenic mineral formation. The other names of these objects are waste deposits, tailing dump and tailing wastes. These objects are formed as the results of gold extraction from gold-bearing ore and placer deposits and special storage of the substance.

Gold is generally considered to be a relatively inert element [7]. However, it can form resistant compounds with halides, sulfides, thiosulfate and amino complexes in the tailing wastes, which can migrate inside wastes $[1-2,8]$. Mechanical and geochemical gold mobility depends on gold forms [4, 7]. As the result of mineral destruction, gold can transform, e.g. dissolve, migrate and precipitate on the geochemical barriers in the wastes [8]. Mineral composition of deposits, gold forms and extraction methods, as well as environmental conditions (climate) influence on gold transformation processes in the supergene zone.

The goal of this project is to gain better insight into gold mineralization inside goldbearing waste through investigation of microcrystalline gold and interfaces between gold and associated minerals. The interface of natural and technogenic processes may elucidate new mechanisms of gold mineralization and conditions of gold growth and dissolution in the supergene environment.

\footnotetext{
*Corresponding author: khusainova@igm.nsc.ru
} 


\section{Materials and methods}

\subsection{Sampling}

For this investigation, technogenic gold samples from several deposits collected in 19842018, were analyzed. Many objects were studied in Russia (Ural, Siberia, Far East), Canada, Uzbekistan and Kazakhstan. There are two categories of mining waste: (i) mine tailings, generated when processing the ore, and (ii) waste rock produced when uncovering the ore body. In our research we studied wastes of type (i), which can be divided into two groups depending on the methods of substance storage and gold extraction: tailings pond (type 1), which is formed as the result of gravitation processes; piles (type 2), which is formed as the results of permanent layering of new portions of coarse-grained material. In this paper we show the results of our study for the following objects. There were dumps of Chernorechenskaya gold placers (Middle Urals), Uderey River (Yenisei Ridge), and gold ore-deposit Tardan (Altai-Sayan folded area) (type 1). There were dumps of the basins of River Iz and River Tura (Middle Urals), Beloklyuchevsky and Novo-Ursky deposits (Salary Range) (type 2).

\subsection{Methods}

The methods of investigation include field and laboratory stages. For type 1, samples were collected along tailings with the step about 5-6 m. For type 2, samples were collected along the profile. Each sample was correlated with the specific lithological layer. Sample volume is about 10-15 liters. Heavy mineral concentrate samples were washed out from the waste in the field by pan and spiral separator according to the methodology of Perm State University (PSU). Gold extraction was completed in the laboratory of geology department PSU, as well as at The V.S. Sobolev Institute of Geology and Mineralogy of the Russian Academy of Sciences (IGM SB RAS). Studies of chemical composition of samples were conducted in Analytical Center for multi-elemental and isotopes research SB RAS, as well as in The Sector "Nanomineralogy" (PSU).

The concentration of gold is measured by the ratio of gold mass to sample volumes. Also, we used the method of atomic absorption spectrometry (SB RAS). We treat the concentrates with the special methods in laboratory conditions. After we chose and describe gold grains under binocular microscope to study in detail. The main results are obtained with the help of a scanning electron microscopy (SEM) a LEO VP 1430 (Carl Zeiss, Germany) INCA Energy SEM 350 (Oxford Instruments), spectrometer in the JEOL 01430VP (IGM SB RAS) and JSM 6390LV in the JEOL (PSU). By comparing gold morphology from wastes and natural objects (placer or deposit), we estimated supergene gold change.

\section{Results}

In this paper, we give only the results for native golds. We obtained the following supergene gold transformations occurring in the wastes: interaction and destruction.

\subsection{Physical and chemical processes}

SEM analysis of crystalline gold sample surfaces from the wastes exhibit various changing morphology of gold particles, for example, the structures of growth and dissolution. This 
changing morphology appears as the result of various physical, chemical and biological processes occurring in exogenic environment.

\subsubsection{Gold integration}

Integration is happening by forming of different films (1), gold growth (2), various mineral compounds, such as: alumo-, iron-, sulfate- and carbonate-, haloid of compositions, as well as impurities of various elements.

We obtained interesting structures of growth on gold surfaces. For example, there were regions of hopper surfaces on gold particles from Beloklyuchevsky deposits. Hopper surface regions cover about $40 \%$ of surface particles, ranging in length from $10 \mu \mathrm{m}$ to 30 $\mu \mathrm{m}$. Individual hopper surfaces typically exhibit either a square or a rectangular morphology. The height of individual hopper depressions vary from approximately $0.5 \mu \mathrm{m}$ to $3 \mu \mathrm{m}$. It is noted that gold skeletal forms originate as the results of fast growth when the electric potential is higher on the edge than in the center of the crystal.

Another proof of gold growth in supergene environment is nano- and micro-gold layers. They are caused by layer-by-layer deposition of matter on growing faces [5, 9]. For example, there are step growth approximately $1 \mu \mathrm{m}$ on the gold surface from Beloklyuchevsky and Novo-Ursky deposits. In addition, a gold-bearing newly formed aggregates are the results of secondary growth. For instance, these phases were discovered on the surfaces of Novo-Ursky gold particles. SEM analysis of these particles shows that phase consists of Se-Au-Ag (\%): Se - 20.1; $\mathrm{Ag}-42.77$; $\mathrm{Au}-26.46$. Selenium is an element-indicator for supergene environment.

Moreover, mineral inclusions are the result of gold growth.

The surface with a protruding relief is formed as the result of precipitation of secondary gold. It is noted that small crystals or roundish aggregates are precipitated on the surfaces of the primary gold. It is possible that it is caused by bacterial activity.

Mercury is an important factor in gold-bearing phase transformation. When gold and mercury interact, aggregation or separation of gold particles can take place. There is native and technogetic mercury in the wastes, which is dissolved under $+20^{\circ} \mathrm{C}$ and interacts with gold easily. Due to the of influence of mercury, nano- and micro-gold phases are aggregated, and therefore conglomerates of gold (to several $\mathrm{mm}$ ) can be formed [10]. For example, as the result of our study of gold from Iz and Tura Rivers we obtained various forms of gold and mercury compounds of different compositions. This transformation is due to diffusion, oxidation, reduction, and electrochemical processes. One of the main products of this transformation is "rusty" gold. However, gold-amalgamated phases can form.

\subsubsection{Differentiation processes}

Differentiation is caused by leaching $\mathrm{Au}$ (1) and $\mathrm{Ag}, \mathrm{Cu}$ (2) from gold surface and formation of a high-concentration border in the near-surface zone of gold particles; the gold phase transforms from hard to liquid or colloid (3).

There are various structures of dissolutions on the particles, for example, the corroded surface with small-cell and spongy reliefs etc. They are formed by interaction between gold and acid drainage water and/or natural organic solvent. Aggressive media components dissolve upper layers of gold and refine its chemical composition. It is noted that these structures form as the result of energetic diffusion of mobile elements $(\mathrm{Ag}, \mathrm{Cu}, \mathrm{Hg}, \mathrm{Se})$ to the environment.

Transformations in composition of particle surface are characterized by changing of chemical composition ratios (increase $\mathrm{Cu}, \mathrm{Ag}, \mathrm{Fe}, \mathrm{Hg}, \mathrm{Co}, \mathrm{Bi}, \mathrm{Pd}$ and decrease gold fines). 


\subsection{Mechanical processes}

\subsubsection{Mechanical processes changing gold forms}

Gold changes in form as the result of mechanical processes, such as destruction or agglomeration of gold particles by the dispersed, colloidal phase, and gold-bearing solutions.

\subsubsection{Mechanical processes for distribution of gold concentration}

By mechanical processes gold is distributed along technogenic mineral formations and form zones of high gold concentration. Gold particles and associated minerals are distributed because of moving substance in water flows along the tailings (type 1). They are precipitated by changing of flow dynamics and gravitational processes. It should be noted that there are several sediment zones: from the receipt point of the material (mouth) to the periphery. Gold particles are distributed from coarse to fine sizes.

For example, in Chernorechenskaya placers there are four zones of minerals distribution, such as a - massive, $\mathrm{b}$ - lenticular, $\mathrm{c}-$ lateral, $\mathrm{d}-$ uniform. There is similar gold distribution in the tailings of Tardan deposits. The concentrations of gold in the mouth part of the dump is $77 \mathrm{mg} / \mathrm{m}^{3}$, at $7 \mathrm{~m}$ from the receipt point of the material in the dump is $2085 \mathrm{mg} / \mathrm{m}^{3}$, and in $17 \mathrm{~m}$ is $86 \mathrm{mg} / \mathrm{m}^{3}$. Gold size decreases from mouth part of dump to periphery. For the tailings of Uderey River, the concentration of gold in the mouth zone is $800 \mathrm{mg} / \mathrm{m}^{3}$, at $6 \mathrm{~m}$ from the point of receipt of the material in the dump is $90 \mathrm{mg} / \mathrm{m}^{3}$, at 17 $\mathrm{m}$ gold is not found.

Gold distribution characteristics for the waste of type 2, which forms as the result of permanent layering of new portions of coarse-grained material. It is noted that a secondary enrichment horizon is formed, for example, Beloklyuchevsky and Novo-Ursky deposits.

\subsection{Biochemical processes}

Biochemical processes are of significant influence on morphology changes of gold. But we do not cover this subject here. Differentiation processes happen by reprocessing of gold via bacteria and fungi (1) with absorption of a part of gold hard phases with formation of soluble forms of gold (2). Gold integration takes place by forming of the membrane-shaped gold structures and bio-form on the surface particles (1), dead gold microfossils (2), and pseudomorphes (3).

\section{Discussion}

Gold undergoes supergene transformation into the exogenous environment. Processes of dissolution, migration and deposition of gold take place under the changing of physical and chemical conditions, namely $\mathrm{pH}$ and Eh.

The problem of these studies is the difficulty of separating natural and technogenic supergene transformations of gold. Now, there are no clear criteria for the separation and diagnosis of such gold. Only experimental work will assess the degree of gold transformation.

However, the liquid phase of gold is very important in these transformations in the waste, which unfortunately is not covered in this paper. 


\section{Conclusion}

1. For the wastes of type 1, rocks are distributed by the principle of mechanical differentiation of minerals. Sedimentation is controlled by changing of the flow dynamics. For the wastes of type 2, rocks form the horizon of secondary enrichment.

2. Morphology and chemical composition of gold changes by exogenous processes. As the result of changing environmental condition, gold can transform, e.g. dissolve, migrate and precipitate on the geochemical barriers in the wastes.

3. Bacteria, fungi and other microorganisms influence the transformation and formation of supergene gold in wastes, which is shown by growth structures on particle surfaces.

4. Gold supergene transformation happens over a short time.

5. The liquid phase of gold is very important in these transformations in the waste.

6. Mineral composition of deposits, gold forms, extraction methods, and environmental conditions (climate) have influence on the gold transformation processes in supergene environment.

Acknowledgements. The article presents the results of the work carried out within the framework of the scientific project by the international research team on the basis of the Perm State National Research University «Development of a nature-like technology for the formation of concentrations of useful components within man-made dumps by controlling the processes of technogenesis». In addition, work is done on stage assignment of IGM SB RAS.

\section{References}

1. D. Craw, D. MacKenzie, P. Grieve, NEW ZEAL J GEOL GEOP, 123-136 (2015)

2. D.M. Falconer, D. Craw, NEW ZEAL J GEOL GEOP, 77-93 (2009)

3. H. Hong, L. Tie, Clays Clay Miner., 162-170 (2005)

4. V.A. Naumov, Mining J. Proc. Univ., 39-50 (1994)

5. B.M. Osovetsky, Spring. Mineral., 145 (2017)

6. N.V. Petrovskaya, Nauka. 253 (1973)

7. A.V. Lalomov, R.M. Chefranov, V.A. Naumov, O.B. Naumova, W. LeBarge, R.A. Dilly, Ore Geol. Rev., 321-335 (2017)

8. F.W. Friese, Econ. Geol., 421-431 (1931)

9. O.B. Naumova, V.A. Naumov, B.M. Osovetskiy, B.S. Lunev, O.N. Kovin, MiddleEast J. of Sci. Res., 316-320 (2013)

10. V.A Naumov., B.M. Osovetsky, Lith. and Min. Res., 37-53 (2013) 